session total 450 full-time and 8,000 part-time students.

The six-storey building consists of a centro block housing the administrative offices, refectory, laboratory and gymnasium-facilities shared by both the Technical College and College of Art-and four wings. 'The two west-wings and the majority of the southeast wing provide accommodation for the Technical College, while the north-east wing is exclusively for the College of Art. Noisy workshops used for mechanical engineering and building have been placed at the lower-ground floor-level, with special construction to keep noise and vibration from affecting the quieter rooms above, while a service road for these workshops runs under the whole length of the building. Lecture rooms, drawing offices and the lighter laboratories and practical rooms for science, electrical engineering, commerce, domestic science and food trades are grouped on the floors above. Lifts and the main staircases situated at the junctions of the two west wings and the two east wings communicate with all teaching floors; other staircases are provided at the extreme ends of the four wings. In the courtyard between the two east wings is situated the Denning Hall, which will seat approximately 750 , and is a gift to the town by Mrs. Elizabeth Denning, in momory of her husband, who was Mayor of Croydon during 1913-16. This fine Hall may be used for the purposes of both Colleges and for other public purposes with an educational association.

Space will permit the detailed description of one Department of the College only, and the Department of Science has been chosen. This Department occupies almost all the fourth-storey accommodation of the two west wings and the centre block. The south-west wing provides laboratories for inorganic, organic and physical chemistry together with balance, store, preparation and dark rooms, a lecture theatre and classrooms. Physics is housed in the north-west wing, and is provided with four laboratories, a workshop, dark room, a lecture theatre, classrooms and stores. Also in this wing is the radioisotopes suite with the X-ray room adjacent. In the centre block on this floor are general seienee and hiology labora- tories together with further class-rooms. Thi accommodation serves the following courses of study :

$\begin{array}{lc}\text { Full-time } & \text { students } \\ \text { General Certificate of Education } & 125 \\ \text { Part-time (daay } & 11 \% \\ \text { General Certificate of Education } & 38 \\ \text { R.Sc. (General) } & 43 \\ \text { Ordinary National Cert. in applied physics } & 43 \\ \text { Higher National Cert. in applied physics } & 43 \\ \text { Graduateship of Institute of Physics } & 9 \\ \text { Ordinary National Cert. in chemistry } & 57 \\ \text { Higher National Cert. in chemistry } & 20 \\ \text { Evening Nation } & 248 \\ \text { General Certificate of Education } & 17 \\ \text { Horticulture } & \end{array}$

In addition, the Science Department acts as it 'service' department by undertaking the teaching of science required by other Departments of the College, for example, Bakery Science.

To provide for unknown expansion in the future. the building is designed on a unit grid with external planning and services as flexible as possible. In the chemistry section, for example, the larger class-room. on the opposite side of the corridor to the existing laboratories are already provided with floor duct and connexions to existing services to permit them being converted readily into extra laboratories. This means that, if additional building is needed. it will be principally class-room accommodation and that the dispersal of the various kinds of department al practical rooms will be avoided.

Many new technical colleges cater for future expansion by building different blocks for different purposes, each of which has a 'growing point' for' extensions. This method may be simpler than that described above; but the Croydon plan, with 'growing points' for class-room accommodation avail. able on the inner sides of the existing east wings, is likely to provide the more compact building with shorter lines of communication for its users.

The integral nature of the building and the decision to place two independent Colleges under one roof are perhaps the most distinctive features of what the Queen referred to as "this imaginative experiment" in which young scientists, technicians, craftsmen and artists may "meet and exchange ideas with those trained in other fields of knowledge".

\title{
BIOLOGY OF SPACE TRAVEL
}

A SYMPOSIUM on the "Biology of Space 'Travel", organized by the Institute of Biology, was held during September 29-30 at the Royal Geographical Society, Kensington.

For the opening session the chair was taken by Sit Lindor Brown. The first paper was by Air-Commodore W. K. Stewart, of the Royal Air Force Institute of Aviation Medicine, Farnborough, who gave an account of recent work on the physiological effects of acceleration. A semi-recumbent posture would allow acceleration for several minutes at about oight times gravity without severe physiological disturbance, and the accelerations on take-off of rockets would be close to this figure. However, little is known about the effects of vibration and of emotional disturbance under such conditions, and in such high accelerations the astronaut would find it very difficult to carry out any movements other than movements of the eyes and of the supported hands. The forces on re-entry would probably reach rather higher' figures, in the region of ten times gravity, and provision would be needed for ensuring that the astronaut was correctly positioned in relation to the decelera. tion ; if this were assured the forces would be toler. able for the short period expected. Wing-Commander T. C. D. Whiteside, also of the Royal Ajr Force Institute of Aviation Medicine, followed with a paper on the effects of the gravity-free state. Although no data are available for man for prolonged periods of weightlessness, it is probable that the physiological effects would not be severe. Eating would be easy, but fluids would have to be sucked from plastic containers. Locomotion would be easy in the dimensions of a small space-vehicle. However. it seems likely that muscular weakness would develop, in a few days due to lack of exertion in a weightless environment, and this might reduce the tolerance to deceleration on re-entry. Regular exercises would 
be needed to combat this problem. An unsuspected difficulty in low gravitational fields might occur if artificial gravity was produced by rotation of the space-vehicle itself, since even in large vehicles the Coriolis forces in the labyrinth of the ear produced on moving the head might give rise to disabling giddiness.

Lieut.-Colonel W. R. 'Turner, of the United States Air Force Aerospace Medical Division, Ohio, described the exacting series of physical and psychological tests "mployed in selecting candidates for the "man-intospace" projects such as "Project Mercury". The candidates were chosen from men with high basic 'pualifications, including a degree in engineering and $2,000 \mathrm{hr}$. of piloting jet aircraft. The examinations included exhaustive medical and psychological examinations and tests under conditions simulating those anticipated in space flight, such as high temperatures, acceleration and vibration. Other tests estimated noise-tolerance, patience with complicated and ('onfusing machinery, and the ability to tolerate long periods of isolation. It was found that, given a normal physique, the motivation of the candidate played a surprisingly large part, and keen but levelheaded men of about thirty-five years were the most successful at these tests.

For the second session the chair was taken by Sir solly Zuckerman. Dr. D. McK. Kerslake read a paper by Flight-Lieutenant J. Billingham, of the Royal Air Force Institute of Aviation Medicine, on the maintenance of the thermal environment in space vehicles. When in orbit the temperature of the (abin would be maintained at a comfortable level by fairly simple air conditioning together with suitable insulation of the walls. On re-entry, however, the frictional heating of the exterior might cause severe over-heating of the interior, particularly if the time for descent was prolonged for any reason. Whether such over-heating will cause skin burns or heat stroke will depend largely on the rate of the rise in temperature. Both these dangers can be avoided by a special suit in which cold air is piped to the skin, and some impressive experiments were cited in which a man was well protected for several hours by this means in an environment at $125^{\circ} \mathrm{C}$.

Mr. N. W. Pirie, of the Rothamsted Experimental Station, Harpenden, discussed the problem of the synthesis or re-cycling of oxygen, food and water on longer space flights. Water is unlikely to be a severe problem since most of the expired water vapour can be readily condensed and distillation of urine would allow the recovery of most of the remainder. The astronaut would require about $1 \mathrm{kgm}$. of oxygen a lay, and the expired carbon dioxide would have to be absorbed : for short voyages potassium tetroxide would be suitable for this dual purpose. For longer voyages it has been suggested that algae such as chlorella could be used to regenerate oxygen and foodstuffs by photosynthesis. There would be many technical problems in this. Outside the orbit of Mars the intensity of sunlight would fall to a level too low for effective photosynthesis: the algae would be very difficult to handle, maintain and process, and they would not in any event be suitable as the sole source of food. Complex chemical resyntheses would require weighty and complex apparatus. An exciting possibility is that some way may be found of readily converting energy into essential biochemical intermediates, so that one could 'recharge' one's energy supplies in a manner analogous to recharging an electric accumulator.
Mr. S. W. F. Hanson, of Armour and Company, Ltd., London, read a paper on the supply of food to astronauts. He described recent progress in packaging food in a suitable form, and in particular the advantages for long journeys of dehydrated and precooked foods, which can be prepared in wide variety this is of great importance from the psychological point of view. He believed that at the most Chlorella would prove to be only an adjunct to the diet of astronauts, even if the technical problems of growing it were overcome. He showed a film which illustrated some of the problems of feeding under conditions of weightlessness.

On the morning of the second day of the symposium Sir Harrie Massey took the chair. Dr. P. Alexander, of the Chester Beatty Research Institute, London, read a paper on radiation in space and its effects on man. Most of the ionizing radiation in space consists of electrons and protons. The majority of the electrons will be stopped by the walls of the space-vehicle, though they will generate $\mathrm{X}$-rays in this process which could penetrate the vehicle; in the inner of the two equatorial Van Allen radiation belts this secondary radiation might deliver a dose of about $5 \mathrm{rads} / \mathrm{hr}$. to the astronaut. The protons, although more penetrating than electrons, would only deliver about $1 \mathrm{rad} / \mathrm{hr}$. The radiation in the outer Van Allen belt would be less than that in the inner belt. In deep space the dose-rate would be small, probably about 10 rads per annum. In a short flight through the Van Allen belts and back the astronaut would receive a total of about $15-20$ rads, which would be well below the permissible level in these special circumstances, and, by choosing a polar route. the radiation would be reduced considerably.

A paper on the psychological problems of solitude and confinement was read by Dr. R. Beech, of the Institute of Psychiatry, Maudsley Hospital, London. Dr. Beech reviewed thoroughly the published research on this topic, and concluded that very little reliable data were available. The tendency for sensory deprivation to cause abnormal mental behaviour, such as hallucinations, was now well recognized, but the degree to which this might occur in space flights was problematic, and little was known on the best ways to combat it. Dr. W. Grey Walter, of the Burden Neurological Institute, Bristol, in a communication entitled "The Human Brain in Space Time", described some recent work on the ability to learn under difficult and confusing conditions, and he emphasized the marked individual variations in the ease with which certain associations were recognized and learnt. He also raised the interesting question of the mental qualities which would be most desirable in astronauts, and noted that outstanding pioneers in many fields have frequently been decidedly eccentric individuals.

The chair in the final session was taken by Dr. A. S. Parkes, president of the Institute of Biology. Dr. P. H. A. Sneath, of the National Institute for: Medical Research, London, discussed the dangers of contaminating the planets with terrestrial microorganisms, or of contaminating the Earth with planetary organisms, should these exist. Recent work suggests that some soil bacteria may be able to multiply under the conditions found on Mars, and if we contaminate Mars with such bacteria the loss of scientific information would be enormous. The sterilization of a space rocket poses some very difficult problems, which urgently need further attention. It would be very dangerous to bring back to the Earth samples from other planets, because of the 
risk that they might contain organisms which could prove dangerous to the ecology of the Earth, and it would be advisable first to earry out experiments on theso in closed cology chambers on manned satellites.

The last paper was by Ir. Harlow shapley of the Harvard Observatory, who discussed the probable environment of other planets. He felt sure that there must be many planets in the univorse which would be suitable for life as we know it on Earth (quite apart from the possibility of life in other forms) and it would seem inevitable that some form of life would have evolved on many of them. Whether we can ever communicate with such worlds was another matter. An important factor in the evolution of higher life may be the ozone layer of the Earth's atmosphere (itsolf due indirectly to the photosynthetic production of oxygen by primitive plants) since this layer protects terrestrial organisms from short- wave ultra-violet rays. None of the other planets of our solar system appears to possess such an ozone layer.

In summing-up, Dr. l'arkes discussed the possibility that astronauts might travel for most of their journey in a state of suspended animation, only to be revived when they reached their destination, and recent work on the freezing of whole animals shows that this is not a wholly faneiful suggestion. This also raises the question of whether man would have a useful part to play in the early stages of space travel, or whether it would be better to dovise very elaborate machines to make the observations. The symposium had the excellent result of bringing together workers in many disciplines, and it showed that the remaining difficulties in short-range space flight were mainly engineering problems, whils: those affecting the astronaut himsclf would soon be largely solved.

\section{INFLUENCE OF CLIMATE ON LIFE}

$\mathrm{O}$ NE of the most obvious, and at the same time one of the most neglected, statements in the whole field of biology is that all life depends on its environment. Biologists and medical men of the past have made this the basis of much of their thinking, and engineers and architects have often built machines or houses to suit specific climates, but scientific journals still contain reports of biological experiments in which the experimental conditions were neither controlled nor recorded, and buildings or vehicles often fail to display any consideration for local climate. Even the impressive Unesco headquarters completed a few years ago in Paris are liable to cause heat exhaustion in people working there on sunny days, and it is well known that motorcars are the hottest places to he found in many tropical cointries.

At the other extreme, tables of comfortable environmental temperatures usually assume that simple mathematical expressions can be valid in biological processes, and ships ply through some of the climatically most pleasant seas of the world carrying with them the same constant artificial micro-climate which can be found in any office building in New York or London.

The International Society for Bioclimatology and Biometeorology held its second International Bioelimatological Congress recently in London with the avowed intention of improving knowledge about the influence of climate on life by bringing together people active in all parts of the world and in all branches of science whose work is related in some way to these problems. The success of the Congress was considerable, and its effects will probably be folt for some time to come. Some of the work helped to cross-fertilize or to dispel misconceptions by passing ideas and techniques between different specialties or different countries, but much new information of interest was also provided.

Symposia included one on life at high altitudes in which Prof. R. Margaria (University of Milan) related the problem of acclimatization to anoxia with space flying where less oxygen means less pressure which, in turn, means less weight. He also reported the results of experiments which showed that the carotid body chemoreceptors of man were sensitive to oxygen, in any event during anoxia, which was of interest in view of occasional criticisms against conclusions made from such studies on anæsthetized animals. A paper by Prof. A. von Muralt and Dr. W. H. Weihe (University of Berre) reported experiments carried out on the Jungfraujoch at about $11,000 \mathrm{ft}$. and mean barometric pressures of about $500 \mathrm{~mm}$. of mercury which showed that the threshold for various stimuli, such as taste, touch or tendon reflexes, was reduced at high altitudes but returned to normal if oxygen was breathed in. Prof. $R$. Schumacher and Dr. R. Schindler (Hamburg) reported on the 'high-altitude disease' observed at about $16,000 \mathrm{ft}$. in the Andes, where cattle developed heart failure and cedema but recovered quickly after a descent of only about $1,500 \mathrm{ft}$., a condition repro. duced experimentally in rats and observed sometimes in man. It is difficult to escape the conclusion from this that the pressures to be chosen for long journeys into space will not be the lowest to which people at rest can bocome acclimatized but the lowest which will avoid heart failure and oedema.

In a symposium on life in the tropics, Prof. Alrick B. Hertzman (University of St. Louis) suggested, among other things, that correlations between the cardiac output and the skin blood-flow were purely coincidental, as there were situations when one was high and the other low, for example, when the skin is cooled after the whole body has been warmed. However, it could equally be argued that the corre. lations between these are part of a system integrating many variables, which usually works in a given way but in which no single correlation is immutably. fixed, thus conforming to what might be predicter in any complex control system and making the relationship betwoon cardiac output and skin blood. flow somewhat more predictable than a mere coineidonce. Dr. H. Boyko (Israel) showed some impres. sive photographs to illustrate how a patch of desert could be turned in a very short time into a lush garden by applying sound principles of bioclimatology. Dr. J. C. D. Hutchinson (now in Parramatta, Aus- 